\title{
Mating behaviour and semen parameters in dromedary camel bulls (Camelus dromedarius): a comparison between two types of artificial vagina
}

\author{
Monaco Davide $^{1 *}$, Fatnassi Meriem ${ }^{2,3}$, Lamia Doghbri², Padalino Barbara ${ }^{1,4}$, Seddik Mabrouk-Mouldi' ${ }^{2,3}$, \\ Khorchani Touhami',3, Hammadi Mohamed ${ }^{2,3}$, Giovanni Michele Lacalandra1 \\ ${ }^{1}$ Department of Veterinary Medicine, University of Bari Aldo Moro, Italy, ${ }^{2}$ Livestock and Wildlife Laboratory, Arid Lands Institute, 4100 \\ Médenine, University of Gabès, Tunisia, ${ }^{3}$ Doctoral School "Science, Engineering and Society"- University of Gabès, Tunisia, ${ }^{4}$ College of \\ Veterinary Medicine and Life Sciences, City University of Hong Kong, HKSAR
}

\section{A B S T R A C T}

\begin{abstract}
Semen collection in the dromedary camel (Came/us dromedarius) is performed using different types of artificial vagina (AV) (long, short, with cervix imitation, with plastic or silicone inner liner) either held by an operator or fitted inside a camel dummy. However, systematic studies about the acceptance of such modifications by bulls, and their effects on sperm parameters, have yet to be investigated. This study was conducted to test the hypothesis that a silicone inner liner inserted into a standard cow AV could cause discomfort to camel bulls during mating, but at the same time could improve the quality of the ejaculates collected. Five bulls underwent semen collection sessions, with $(n=3)$ and without $(n=3)$ the silicone liner fitted in the AV, for a total of 30 semen collection sessions. A standard methodology and data-recording system were used for evaluating mating behavior, in addition to evaluation of semen parameters. There was no difference between an AV with or without silicone inner liner used during our standardized semen collection procedure. The use of such an AV modification hence still remains debatable, until further studies are able to identify any potential benefits of using this or other AV types or modifications. Such studies, however, should be performed by applying a standardized semen collection methodology and a proper evaluation of mating behaviour and semen parameters.
\end{abstract}

Keywords: Artificial vagina; Ejaculates; Inner liner; Mating behavior; Refractory period; Standardized procedure

\section{INTRODUCTION}

In the dromedary camel (Camelus dromedarius), semen collection presents peculiarities and difficulties (Tibary and Anouassi, 1997). The techniques used include artificial vagina (AV), camel dummy, or electro-ejaculation. Each technique has advantages and disadvantages, resulting in a wide range of variability in terms of sperm harvesting (El-Hassanein, 2003; Musa et al., 1993; Vyas et al., 1998; Ziapour et al., 2014).

The AV could be inserted in the camel dummy or else held by an operator. Although different AV types or modifications are currently in use, no exhaustive research into the most suitable one has been performed. For instance, El-Badry et al. (2017) and Ziapour et al. (2014) used a $30 \mathrm{~cm}$ long AV with a $5 \mathrm{~cm}$ inner diameter and a foam cervix imitation (according to indications by Bravo et al., 2000), whereas El-Bahrawy, in 2010, used the same kind of AV without the cervix imitation. Since it is believed that sperm motility could be affected by contact with the AV rubber or with the AV collection funnel, all the above authors applied a plastic liner inside the AV cylinder (El-Badry et al., 2017; El-Bahrawy, 2010; Ziapour et al., 2014). Skidmore et al. (2013) reported that the disposable inner liner was not well accepted by the bulls, and Cholakkal et al., (2016) reported that the use thereof was unsuitable because the collected ejaculates 'stick' to the liner, were 'frothy' and of low volume. However, except for Cholakkal et al. (2016), none of these authors carried out any investigations in order to assess the benefits or disadvantages of using a particular AV type or modification. Deen et al. (2003b) evaluated sperm motility using a camel collection glass (IMV, France) directly connected with the

\footnotetext{
${ }^{*}$ Corresponding author:

Dr. Davide Monaco DVM, PhD, Department of Veterinary Medicine, University of Bari Aldo Moro, Road to Casamassima Km 3,70010

Valenzano (Ba), Italy. E mail: monaco_davide@libero.it
} 
$\mathrm{AV}$, and compared this with the standard rubber connection funnel, but detected no significant differences. Skidmore et al. (2013) stated that short AVs were more popular, but it is unclear whether they were referring to the same AV as described in Deen et al. (2003b); there is no description about the characteristics of such short AVs (length of the cylinder, collection funnel and preparation) and about comparison with other types of AV.

Morton et al. (2008) developed an AV silicone inner liner for semen collection in Alpaca and subsequently also used this liner to collect semen from dromedary camel bulls (Morton et al., 2013). This AV modification, however, was not compared with other AV types in order to evaluate its acceptance by the bulls or differences in sperm harvest or semen parameters (Morton et al., 2013). Comparing different types of $\mathrm{AV}$, low yield of semen using the foam imitation cervix and a high percentage of mating interruptions using the silicone inner liner were obtained (Cholakkal et al., 2016). These authors concluded that there was no advantage in using such modifications and suggested using a $30 \mathrm{~cm}$ bovine $\mathrm{AV}$ with a short collecting cone and a wide-mouthed collection vial. However, their observations were performed on males (8-14 years old) untrained in semen collection, and each AV type was excluded from the trial after three refusals by the males to serve into it (Cholakkal et al., 2016). In addition, mating and semen parameters were not adequately taken into account.

Considering all the above issues, modifications to the artificial vagina and their effects on camel bull mating behavior, sperm harvest, and seminal parameters are still worthy of investigation. Moreover, given the importance of semen collection for male breeding soundness evaluation (Chenoweth and McPherson, 2016), a standard semen collection procedure for performing similar evaluations was required.

The aim of this study was therefore to evaluate the effect of a silicone inner liner on dromedary bull mating behavior and semen parameters, using a standardized semen collection method. Our hypothesis was that use of the silicone inner liner could affect mating behavior parameters but, at the same time, improve the quality of the ejaculates collected.

\section{MATERIAL AND METHODS}

\section{Ethical statement}

All procedures were conducted in accordance with the Directive for the Protection of Experimental Animals (2010/63/EU); applicable international, national, and/ or institutional guidelines for the care and use of animals were followed. The experiment was approved by the Ethics Committee for Veterinary Clinical and Zootechnical Studies (Department of Emergency and Transplantation of Organs, D.E.T.O. University of Bari Aldo Moro, Italy).

\section{Location of the study and animals}

Semen collection sessions were performed at the Arid Lands Institute experimental station (Médenine, Tunisia $\left.33^{\circ} 30^{\prime} \mathrm{N}, 10^{\circ} 40^{\prime} \mathrm{E}\right)$ from 25 February 2015 to 18 March 2015 . Five healthy dromedary bulls, three aged ten years and two aged seven and eight years respectively, were used. The animals had been trained in the semen collection procedure and with the AV during the 2012-2013 and 2013-2014 breeding seasons and were completely accustomed to the procedure. The bulls were housed in single boxes with sand bedding (height $=3 \mathrm{~m}$, length $=5 \mathrm{~m}$, and width $=3 \mathrm{~m}$ ) and each day, one by one, were left free to walk in the paddock facing the box for one hour (Fatnassi et al., 2014). Animals were fed oat hay and $2 \mathrm{~kg}$ concentrate supplement (barley, wheat bran, olive cake, minerals and vitamins) daily and provided drinking water, ad libitum, once in two days.

\section{Experimental procedure}

The bulls underwent semen collection twice a week: six semen collection sessions were performed per male, $\mathrm{n}=3$ with a cow AV (CAV) and $\mathrm{n}=3$ with the same AV having a silicon inner liner (SILAV), for a total of 30 semen collection sessions. The semen was collected on an alternate basis: once with the CAV and once with the SILAV. Males were allocated randomly to one or other of the experimental groups.

\section{Preparation of the silicone inner liner and of the artificial vagina}

A silicone liquid gel (Platsil gel $₫ 10$, Neill's Materials, UK) was prepared by adding an equal volume of part $\mathrm{A}$ and part B, according to the manufacturer's instructions. After mixing, the gel was applied with a disposable brush onto a plastic pipe (length $50 \mathrm{~cm}$, diameter $3 \mathrm{~cm}$ ). Once the first layer had dried/consolidated, another mix was prepared and a new layer was gently applied. A total of 4 to 6 silicone layers were applied, taking care to homogeneously distribute the silicone, during layer consolidation, and ensuring that no silicone dripped from the pipe during layer consolidation. The liner was removed from the pipe before complete consolidation (Stuart Cassie, personal communication in 2014).

The AV (IMV ${ }^{\circledR}$, France), with or without the inner liner, was filled with warm water and, before and after each mount, its temperature was regularly checked with a thermometer (Aquatic Eco-System, Inc ${ }^{\circledR}$ ) ensuring that the inner temperature was between 40 and $42^{\circ} \mathrm{C}$. The AV water was replaced, if required, according to the 
duration of the semen collection and climatic conditions. A graduated $15 \mathrm{ml}$ glass or falcon tube jacketed in an infant feeding bottle filled with water at $37^{\circ} \mathrm{C}$ was applied for the collection of semen at the end of the short funnel. Where the silicone inner liner was used, one side was fitted around the AV and the other side ended near the mouth of the funnel (Photo 1 and 2). The last part of the AV was protected with a thermal-insulation bag, for protecting the connection funnel and the infant feeding bottle with the falcon tube (Photo 3).

\section{Semen collection}

Semen collection sessions were carried out twice a week, always in the same conditions, starting from 9.00 a.m., in the walled paddock outside the males' stalls $(10 \mathrm{~m}$ x $25 \mathrm{~m})$, following the procedure previously described (Padalino et al., 2015; Monaco et al., 2016). Briefly, a female camel was led into the paddock, restrained in sternal recumbence and her back protected with a cloth saddle to avoid lesions caused by the males' sternal pad. Once the operators were ready, the door to the male stall was opened. When the male mounted the female, the operator approached from

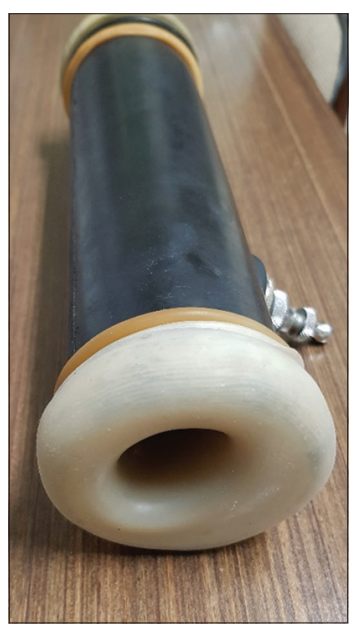

Photo 1. The silicone inner liner fitted on the opened side of the AV.

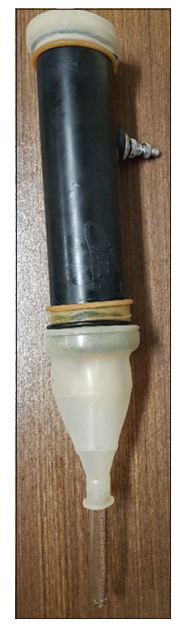

Photo 2. AV with collection funnel and graduated glass tube. the left, grabbed the preputial sheath and deviated the penis into the AV. The time spent copulating with the AV was recorded as "Mating time".

After copulation and dismount, the male was left to move freely around the paddock and two behaviors could be observed: a) the male stood on or near the female (Standing on the female time) for a variable time (sniffing her and performing flehmen), then sat on her again and started another service; b) the male walked around the paddock sniffing the soil or showing dominance behaviors (urination and tail flapping, poll gland scratching on door and walls) toward the door of another male. In the latter situation, a six-minute period of "Walking time" (modified from Padalino et al., 2015) was computed, after which the male was gently led toward the female using the halter rope; if the male refused to approach the female, he was given another six minutes, at the end of which another attempt was made to lead him toward the female. A maximum of three attempts were made after each copulation (i.e. $3 \mathrm{x}$ 6 minutes walking time). During the six-minute walking time, or while the male was standing over the female, the AV falcon tube, the AV water, or the whole AV, were replaced for prompt evaluation of the ejaculate, in order to keep the internal temperature of the AV at 40-42 $\mathrm{C}^{\circ}$, and/ or to avoid contamination of the subsequent ejaculates, respectively. If not particularly soiled, the open side of the AV was cleaned with a paper towel.

The semen collection session was considered to be complete i) if a latency time (time from door opening to the start of mating) of 15 minutes was reached without any mount or ii) if the male refused to approach the female and mount again, after the previous service and subsequent $3 \mathrm{x}$ 6 minutes walking time or iii) if the collection session had lasted 45 minutes (modified from Padalino et al., 2015).

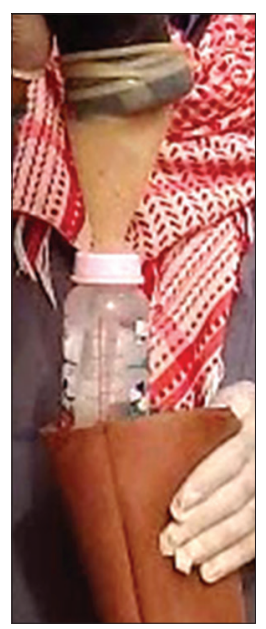

Photo 3. AV with infant feeding bottle applied the collection tube and thermal insulation bag. 


\section{Semen Evaluation}

For each semen collection session, the number of ejaculates was recorded and each ejaculate was individually evaluated for the following parameters: color (gray, white, and milkywhite), volume, viscosity, motility score, sperm viability and sperm concentration (Tibary and Anouassi, 1997). The viscosity of ejaculates was evaluated through the thread test (Kershaw-Young et al., 2013) and the sperm motility was scored from 0 to $5(0=\max 10 \%$ of sperm motility; $1=10-20 \% ; 2=20-40 \% ; 3=40-60 \%, 5=$ above $80 \%$ ), after mixing a drop of semen with an equal volume of PBS and observing it under a microscope. Due to the high viscosity of the seminal plasma, both oscillatory and forward movements of the sperm were considered (KershawYoung et al., 2013; Zeidan et al., 2014). The viability of the spermatozoa was evaluated on Eosin/Nigrosin stained slides (Malo et al., 2017; Tibary and Anouassi, 1997). The sperm concentration was evaluated, using a hemocytometer, after the spontaneous, complete liquefaction of the ejaculates and dilution (1:100) with a $0.5 \%$ formaldehyde solution (Monaco et al., 2015; Monaco et al., 2016; Wani et al., 2008). The ejaculates were categorized into four classes: A (Concentration $>100 \times 10^{6} \mathrm{spz}$, Motility score $\geq$ 2); B (Concentration $<100 \times 10^{6} \mathrm{spz}$, Motility score $\geq 2$ ); C (Concentration $>100 \times 10^{6} \mathrm{spz}$, Motility score < 2); D (Concentration $<100 \times 10^{6} \mathrm{spz}$, Motility score $<2$ ).

\section{Evaluation of mating parameters}

For each collection session, the following mating parameters were recorded: copulation/service time (time of a single mount with the AV giving an ejaculate), standing on the female time, walking time, total mating time (sum of all copulation/service time within a collection session), total number of mounts, number of mounts without ejaculation (modified from Monaco et al., 2016). In addition, after each session, the observer assigned the male a Libido score, from 0 to 5: $0=$ no sexual interest and latency time of over 15 minutes; $1=$ the male approaches the female, sniffs her, mounts her, sits for copulation then dismounts (only 1 attempt to mount); $2=$ the male approaches the female, sniffs, takes position and copulates only once; $3=$ the male copulates more than once and between two mounts stands over/near the female showing flehmen, whistling, neck touching, but sometime spends time walking; $4=$ The male copulates more than once and between two mounts stands over/near the female showing flehmen, whistling, neck touching, blathering, dulaa extrusion, tail beating and sometimes walks away from the female; $5=$ The male behaves as in score 4 but rarely walks around (Padalino et al., 2015).

\section{Statistical analysis}

Average values of copulation/service time and total mating time were calculated per ejaculate and AV type (CAV,
SILAV), respectively, and the same procedure was applied regarding ejaculate parameters.

Single ejaculates and the sum of all ejaculates collected within a session were analyzed. The normality of the sperm's quantitative (i.e. volume, viscosity, viability, motility score, sperm concentration) and of the behavioral (i.e. copulation/service time, total mating time, total number of mounts, number of mounts with ejaculation, number of mounts without ejaculation, libido score) variables were checked using the Anderson-Darling test. As they were not normally distributed, data were statistically analyzed by the Mann-Whitney U test using GenStat 64-bit Release 16.2. The factor was the AV type (AV, SILAV) and data were expressed as mean \pm standard deviation. The Chisquare test was used to evaluate the association between AV type (CAV, SILAV) and ejaculate class (A, B, C, D).

Ejaculates collected within the same session (EJ1, EJ2, EJ3, EJ4) underwent analysis of variance using the NPAR1WAY procedure by SAS (SAS, 2012). When the model was significant, the Waller-Duncan K-ratio $t$ test was used as a multiple range test. Results are presented as mean \pm standard deviation (SD). The only qualitative dependent variable (i.e. ejaculate color) was analyzed using the PROC FREQ procedure and results presented as percentages. $P$ value was always set at 0.05 .

\section{RESULTS}

Twenty-nine collection sessions were successful. There was a latency time $>15$ min for one semen collection, which was therefore cancelled. Fourteen semen collections were performed with the silicone inner liner and fifteen without. Within the collection sessions, a mean of five mounts was recorded and about three ejaculates per session were obtained (Table 1).

A total of $21 \%$ of the sessions yielded only one or two ejaculates; three or four ejaculates were collected in 58\% and five or more in about $21 \%$ of cases (Figure 1). A total of 58 and 46 ejaculates were collected with SILAV and CAV, respectively (Figures 2 and 3).

With the CAV, three or four ejaculates were collected in about $65 \%$ of semen collection sessions, whereas the SILAV led to three or four ejaculates in less than $50 \%$ of sessions but to a higher number of ejaculates (i.e. 5 to 7 ) in $30 \%$ of the collections (Figures 2 and 3 ).

Mean parameters of the collected ejaculates were: Volume $4.49 \pm 2.43 \mathrm{~mL}$; Viscosity $6.30 \pm 3.34 \mathrm{~cm}$; Motility Score $2.40 \pm 1.66$; Viability $48.66 \pm 24.93(\%)$; Concentration $394.3 \pm 567.2\left(\mathrm{spz} \times 10^{6} / \mathrm{mL}\right)$ 
Table 1: Mating behaviour parameters and mean number of ejaculates obtained during each semen collection session ( $\mathrm{n}=\mathbf{2 9}$ )

\begin{tabular}{|c|c|c|c|c|c|c|c|c|c|c|}
\hline Parameter & $\begin{array}{l}\text { Copulation/ } \\
\text { service } \\
\text { time (s) }\end{array}$ & $\begin{array}{l}\text { Standing on } \\
\text { female (s) }\end{array}$ & Walking (s) & $\begin{array}{c}\text { Total } \\
\text { mating } \\
\text { time (s) }\end{array}$ & $\begin{array}{l}\text { Libido } \\
\text { score }\end{array}$ & $\begin{array}{l}\text { Number of } \\
\text { mounts (n) }\end{array}$ & $\begin{array}{l}\text { Mounts without } \\
\text { ejaculation }(n)\end{array}$ & $\begin{array}{c}\text { Obtained } \\
\text { ejaculates (n) }\end{array}$ & $\begin{array}{l}\text { Ejaculates } \\
A \text { and } B(n)\end{array}$ & $\begin{array}{l}\text { Ejaculates } \\
C \text { and } D(n)\end{array}$ \\
\hline Mean & 718.16 & 666.7 & 511.8 & 1957 & 2.92 & 5.54 & 1.9 & 3.53 & 2.13 & 1.4 \\
\hline Min & 44 & 0 & 0 & 1095 & 0 & 1 & 0 & 1 & 0 & 0 \\
\hline Max & 1310 & 1967 & 1394 & 2916 & 5 & 11 & 5 & 7 & 4 & 4 \\
\hline SD & 347.8 & 520.2 & 438.9 & 551.5 & 1.50 & 2.39 & 1.52 & 1.53 & 1.40 & 1.22 \\
\hline
\end{tabular}

A (Concentration $>100 \times 10^{6} \mathrm{spz}$, Motility score $\geq 2$ ); B (Concentration $<100 \times 10^{6} \mathrm{spz}$, Motility score $\geq 2$ ); C (Concentration $>100 \times 10^{6} \mathrm{spz}$, Motility score $<2$ ); $\mathrm{D}$ (Concentration $<100 \times 10^{6} \mathrm{spz}$, Motility score $<2$ )

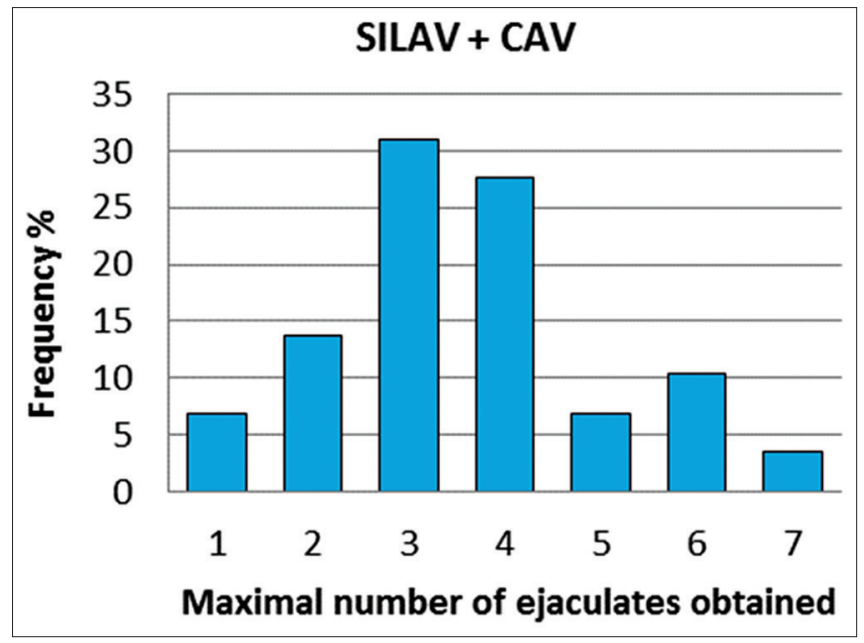

Fig 1. Maximal number of ejaculates obtained during collection sessions $n=29$.

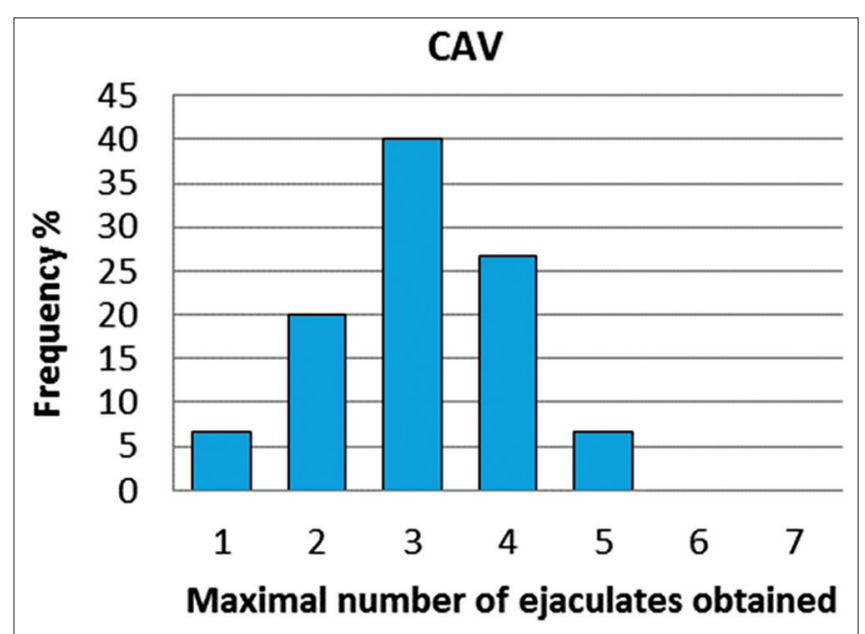

Fig 2. With a cow artificial vagina (CAV: $n=14)$.

Interejaculate differences (EJ1-EJ4) are reported in Table 2; sperm concentration decreased significantly from first to fourth ejaculate, in concomitance with an increase in ejaculate viscosity.

AV type did not exert any significant effect on either mount or ejaculate parameters (Tables 3 and 4).

There was no association between the type of AV and the class $\left(\mathrm{X}^{2}=5.97 ; \mathrm{P}=0.201\right)$ (Figure 4 ) or color of ejaculates $(\mathrm{P}=0.4364)$ (Figure 5).

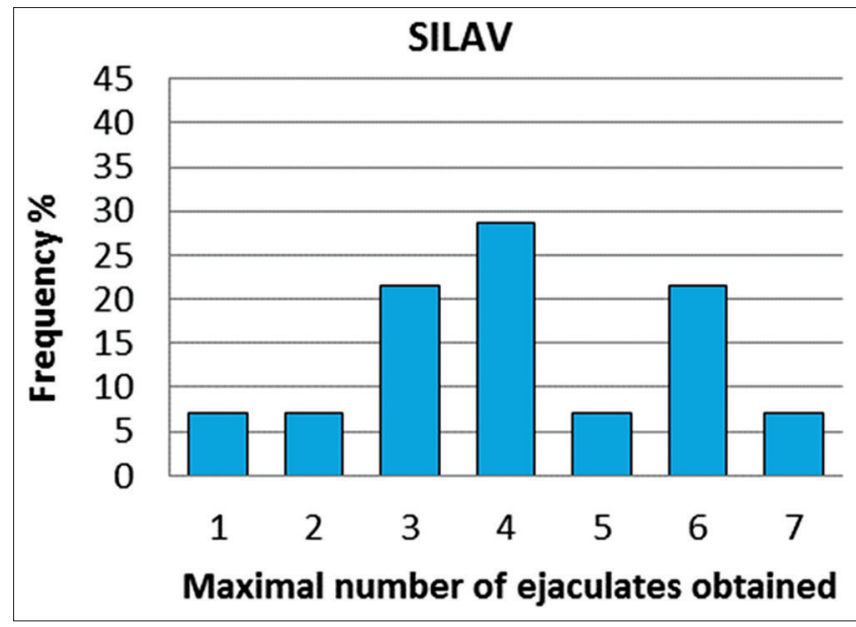

Fig 3. And with a silicone inner liner artificial vagina (SILAV: $n=15$ ), respectively.

\section{DISCUSSION}

The two types of AV used in the present study had no effect on the parameters regarding mating behaviour and semen parameters; the hypothesis that the silicone inner liner could affect mating behaviour and improve semen parameters was not supported by the observed data. However, this study documents, for the first time, the mating bevarioural parameters (copulation/service time, total number of mounts, number of mounts with and without ejaculation, total mating time) and the characteristics of the collected ejaculates (number, volume, viscosity, sperm motility, sperm viability and sperm concentration) by using a standardized semen collection methodology and recording system. The methodology described in this study and the resulting data could, therefore, improve knowledge of reproductive physiology in dromedary camel bulls, contribute to the standardization of the semen collection procedure and to the development of assisted reproductive technologies (i.e., artificial insemination) in this species.

Surprisingly, the application of the silicone inner liner to the AV did not cause any discomfort to the males during copulation: no significant variations were detected on total mating time, on the number of mounts and on the quality of the collected ejaculates. This finding agrees with previous report of Deen et al. (2003) and confirms that 
Table 2: Semen parameter variations among collected ejaculates (EJ1-EJ4, n=93)

\begin{tabular}{lcccc}
\hline Parameter & EJ1 & EJ2 & EJ3 & EJ4 \\
\hline Mount duration $(\mathrm{s})$ & $180.2 \pm 98.8$ & $194.6 \pm 99$ & $215.9 \pm 138.1$ & $243.4 \pm 182$ \\
Ejaculate volume $(\mathrm{mL})$ & $4.0 \pm 1.9$ & $4.7 \pm 2.4$ & $4.7 \pm 3.2$ & $5.8 \pm 2.5$ \\
Ejaculate viscosity $(\mathrm{cm})$ & $5.0 \pm 3.4^{\mathrm{b}}$ & $6.1 \pm 3.1^{\mathrm{ab}}$ & $7.5 \pm 3.6^{\mathrm{a}}$ & $7.7 \pm 2^{\mathrm{a}}$ \\
Ejaculate viability $(\%)$ & $53.5 \pm 22.8$ & $51.2 \pm 27.7$ & $46.4 \pm 27.3$ & $49.5 \pm 22.1$ \\
Ejaculate motility score $(0-5)$ & $2.7 \pm 1.7$ & $2.4 \pm 1.9$ & $2.3 \pm 1.5$ & $2.6 \pm 1.7$ \\
Ejaculate sperm concentration $\left(10^{6} \mathrm{Spz} / \mathrm{mL}\right)$ & $614.6 \pm 727.6^{\mathrm{a}}$ & $518.4 \pm 641.3^{\mathrm{ab}}$ & $249.2 \pm 318.9^{\mathrm{ab}}$ & $169.7 \pm 125^{\mathrm{b}}$ \\
\hline
\end{tabular}

Within the same row, different letters $(a, b)$ statistically differ by $P<0.05$

Table 3: Mating behaviour and ejaculate parameters obtained with different types of artificial vagina (AV): cow AV (CAV) vs silicone inner liner AV (SILAV)

\begin{tabular}{|c|c|c|c|c|}
\hline Parameter & CAV $\left(n^{\circ} 14\right)$ & SILAV $\left(n^{\circ} 15\right)$ & $\mathbf{U}$ & $\mathbf{P}$ \\
\hline Copulation/service time (s) & $642.3 \pm 281.7$ & $794.9 \pm 400$ & 57 & 0.169 \\
\hline Standing on female (s) & $632.3 \pm 534.1$ & $701 \pm 525.3$ & 74 & 0.614 \\
\hline Total mating time (s) & $1880 \pm 500.9$ & $2033 \pm 608.3$ & 73 & 0.579 \\
\hline Libido score & $2.54 \pm 1.33$ & $3.30 \pm 1.60$ & 63 & 0.267 \\
\hline Number of mounts $(n)$ & $5.46 \pm 1.94$ & $5.61 \pm 2.84$ & 83 & 0.949 \\
\hline Mounts without ejaculation (n) & $2.23 \pm 1.48$ & $1.61 \pm 1.55$ & 64 & 0.290 \\
\hline Obtained ejaculates (n) & $3.13 \pm 1.06$ & $3.93 \pm 1.83$ & 81.5 & 0.194 \\
\hline Ejaculates A and B (n) & $1.8 \pm 1.47$ & $2.47 \pm 1.30$ & 82.5 & 0.222 \\
\hline Ejaculates $C$ and D (n) & $1.33 \pm 1.11$ & $1.46 \pm 1.35$ & 108 & 0.882 \\
\hline
\end{tabular}

Table 4: Mean ejaculate parameters obtained with different types of artificial vagina (AV): cow AV (CAV) vs silicone inner liner AV (SILAV)

\begin{tabular}{lcccc}
\hline Parameter & CAV $\left(\mathbf{n}^{\circ} 14\right)$ & SILAV $\left(\mathbf{n}^{\circ} 15\right)$ & U & P \\
\hline Volume $(\mathrm{mL})$ & $4.291 \pm 2.459$ & $4.653 \pm 2.423$ & 1193 & 0.291 \\
Viscosity $(\mathrm{cm})$ & $6.538 \pm 3.441$ & $6.116 \pm 3.267$ & 1241 & 0.545 \\
Mass motility & $2.198 \pm 1.903$ & $2.555 \pm 1.442$ & 1040 & 0.305 \\
score & & & & \\
Viability (\%) & $48.15 \pm 28.97$ & $49.7 \pm 21.54$ & 1153 & 0.835 \\
Concentration & $443.2 \pm 622.8$ & $356 \pm 516.4$ & 1104 & 0.557 \\
$\left(\right.$ spz $\left.\times 10^{6}\right)$ & & & & \\
\hline
\end{tabular}

the silicone inner liner may be used, as well as the standard $\mathrm{AV}$, for collecting semen in dromedary camel bulls (Morton et al., 2013). However, if no significant differences or clear benefits can be ascertained, the choice of particular AV type or AV modification for collecting dromedary camel semen, still remains debatable.

Our results are in contrast with those of Cholakkal et al. (2016) who observed a higher number of dismounts (70\%) when using the SILAV as compared with the CAV (24\%) and stated that the latter is the most suitable AV type for dromedary camel bulls. The present study was carried out in the middle of the breeding season, when the camel bulls' libido was at its peak, and with bulls previously trained for semen collection. In contrast, previous authors started their observations at the beginning of the breeding season and with bulls which had not previously been trained for semen collection (Cholakkal et al., 2016). It may be possible, therefore, that the camel bulls' lack of experience (in serving into the AV) and their low mating libido, typical for the beginning of the breeding season (Deen, 2008),

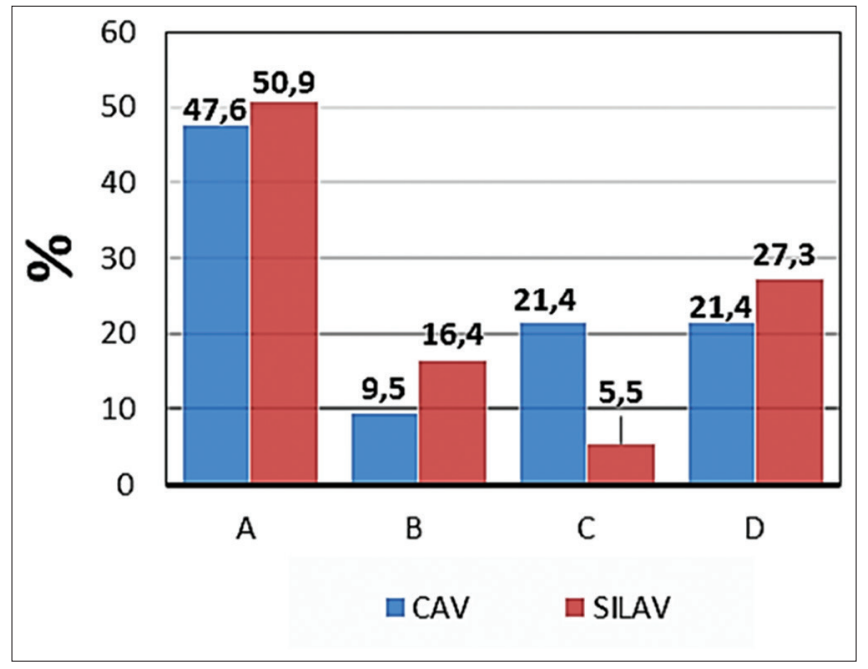

Fig 4. Quality of ejaculates collected with different types of artificial vagina (AV): cow AV (CAV) vs silicone inner liner AV (SILAV). Pearson chi-square value 5.97, 4 d.f., $P=0.201$. A (Concentration $>100 \times 10^{6}$ $\mathrm{spz}$, Motility score $\geq 2$ ); B (Concentration $<100 \times 10^{6} \mathrm{spz}$, Motility score $\geq 2$ ); C (Concentration $>100 \times 10^{6} \mathrm{spz}$, Motility score < 2); D (Concentration $<100 \times 10^{6} \mathrm{spz}$, Motility score <2).

may have given the impression that the silicone inner liner modification is unsuitable for collecting semen.

In addition, in the above-mentioned study, the AV temperature range was set from $35^{\circ}$ to $42^{\circ} \mathrm{C}$ (Cholakkal et al., 2016). Temperatures below $40^{\circ} \mathrm{C}$ may cause more frequent dismounting, although other factors could be mentioned (training procedure, male's experience, operator). The thickness of the silicone liner offers an additional thermal barrier and reduces heat exchange; hence, this modified AV needs to be prepared with warmer 


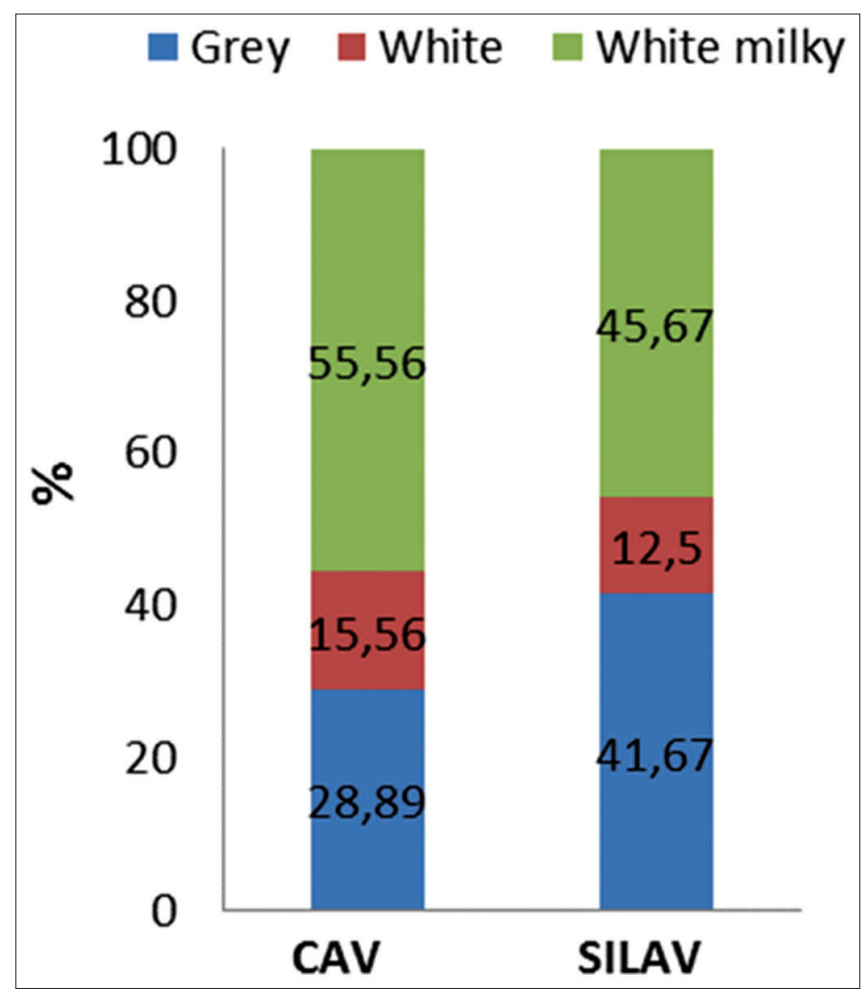

Fig 5. Color percentages of ejaculates collected with artificial vagina (AV): cow AV (CAV) vs silicone inner liner AV (SILAV). $P=0.4364$

water (as compared with the normal AV) to achieve an inner temperature of $40-42^{\circ} \mathrm{C}$. As per our previous observations, and contrary to Cholakkal et al., (2016), dismounting should be considered normal behavior, after ejaculation, when collecting semen by $\mathrm{AV}$; it may indicate a male's discomfort (e.g. AV temperature below $39^{\circ} \mathrm{C}$ or above $43^{\circ} \mathrm{C}$, low or high pressure of the inner chamber), but only if dismounting occurs immediately after insertion of the penis into the AV.

References to semen collection in camels reveal a great variation in service duration (2-20 minutes), volume of ejaculate (3-15 mL) and sperm concentration (300 to $800 \times 10^{6}$ sperms) (Agarwal and Kanna, 1990; Deen et al., 2003a; El-Hassanein, 2003; Hammadi et al., 2008; Tibary and Anouassi, 1997). However, since those studies reported neither the collection procedure nor the behavioral data (total mating time, number of mounts), a true comparison between different studies could not be performed.

To our knowledge, a standardized semen collection method and the data-recording system used in this study have never been reported in the literature, even though this is mandatory in order to properly evaluate male breeding performance as well as the suitability of different types of artificial vagina for semen collection. The standardized semen collection protocol and the datarecording system proposed in this study, if applied on a large scale, would allow a true comparison of data among males from different breeding centers and contribute to the standardization of the breeding soundness evaluation of dromedary camel bulls. Its routine application and further improvements should, however, be discussed among the camel scientific community.

"During semen collection, the bull makes several thrusts, interspersed by periods of rest, until ejaculation is complete" (Skidmore et al. 2013). Following ejaculation, all males experience a refractory period before a second ejaculation can occur, and the length of this interval depends on several factors: degree of sexual rest prior to copulation, age, female novelty, number of previous ejaculations (Senger, 2005). A walking time (3 x 6 minutes) was introduced into the semen collection schedule to provide a chance to express natural mating behavior, after ejaculation and dismounting. This procedure most probably gave the males time to recover from the post-ejaculation refractory period and, as per the past and present results, improved the number and quality of the ejaculates (Padalino et al., 2015).

In the present study, a mean of about 5 mounts per semen collection session and 3 ejaculates were noticed. The mean ejaculate parameters are similar to the results obtained in other studies (Al Bulushi et al., 2016; Morton et al., 2011; Ziapour et al., 2014; Wani et al., 2008) whereas the results obtained within each semen collection session (total mating time, total number and volume of ejaculates) are very similar to the highest range of mating duration, ejaculate volume and sperm concentration values obtained with a standard AV (Deen et al., 2003a), and with the AV (with cervix imitation) positioned in the camel dummy (ElHassanein, 2003).

The differences observed from the $1^{\text {st }}$ to the $4^{\text {th }}$ ejaculates (i.e., decrease in sperm concentration and increase in volume and viscosity) are in agreement with previous observations (Fatnassi et al., 2016) and could be due to the reduction in sperm reserves as well as to the role of the camelid seminal plasma as a "plug" or "sperm reservoir" during the timeframe between mating and the induced ovulation (Brown, 2000). Hence, as the number of mounts increase, there was a decline in sperm concentration and an increase in seminal plasma, which would also explain the higher viscosity of the later ejaculates. This finding may suggest that the semen collection session should be ended after obtaining a maximum of three to four ejaculates. However, since breeding bulls are capable of several mounts per day, further studies have to be performed to assess daily sperm output according to age, nutritional status, genetic, breeding system and rearing conditions (Fuerst-Waltl et al., 2006; Mathevon et al., 1998; Sieme 
et al., 2004).

\section{CONCLUSIONS}

No difference was observed between an AV with or without a silicone inner liner used during our standardized semen collection procedure. It seems therefore that the use of a silicone inner liner does not affect mating behaviour in dromedary camel bulls, nor does it improve the parameters of the collected ejaculates. The use of this AV modification hence remains debatable, unless further studies can identify potential benefits using this or other AV types or modifications. Such studies, however, should be performed using a larger dataset, applying a standardized semen collection methodology and a proper evaluation of mating and semen parameters.

\section{STATEMENT}

This document was produced with the financial assistance of the European Union through the "PROCAMED" Project: Promotion des systèmes camelins innovants et des filières locales pour une gestion durable des territoires sahariennes: reference number: I.B/1.1/493. The contents of this document are the sole responsibility of the Veterinary Clinic and Animal Production Section (D.E.T.O) Bari (Italy) and of the Livestock and Wildlife Laboratory, IRA Médenine (Tunisia), and can under no circumstances be regarded as reflecting the position of the European Union.

\section{AUTHOR CONTRIBUTION}

DM, MH, MF and PB conceived the study; MF, FE, MMS and DM performed the experimental trial; $\mathrm{MH}, \mathrm{MF}$ and BP performed the statistical analysis; DM interpreted the data and wrote the manuscript; BP, MH, TK and GML revised the final manuscript. The contribution of M. Kchira Belgacem for animal handling and semen collection procedure is greatly acknowledged. The authors also acknowledge Anthony Green for proofreading and providing linguistic advice. All authors have read and approved the final manuscript and declare they have no conflict of interest.

\section{REFERENCES}

Agarwal, S.P. and N.D. Khanna. 1990. Endocrine profiles of Indian camel under different phases of reproduction. In: Proceedings of the workshop "Is it possible to improve the reproductive performance of the camel?" Paris. P 77-100.

Al-Bulushi, S., B.M. Manjunatha, R. Bathgate and S.P. De Graaf. 2016. Characteristic of semen collected from dromedary camel bulls. In: Proceedings of the ICAR Satellite meeting on Camelid Reproduction. France. P 69-73.

Bravo, P.W., J.A. Skidmore and X.X. Zhao. 2000. Reproductive aspects and storage of semen in camelidae. Anim. Reprod. Sci. 62: 173-193.

Brown, B.W. 2000. A review on reproduction in South American camelids. Anim. Reprod. Sci. 58: 169-195.

Chenoweth, P.J. and F.J. McPherson. 2016. Bull breeding soundness, semen evaluation and cattle productivity. Anim. Reprod. Sci. 169: 32-36.

Cholakkal, I.K., A. Koroth and S. Al-Sharifi. 2016. Observation on semen collection and suitability of different modifications of Artificial Vagina from dromedary camels (Camelus dromedarius). J. Camel Pract. Res. 23: 169-174.

Deen, A. 2008. Testosterone profiles and their correlation with sexual libido in male camels. Res. Vet. Sci. 85: 220-226.

Deen, A., S. Vyas and M.S. Sahani. 2003a. Semen collection, cryopreservation and artificial insemination in the dromedary camel. Anim. Reprod. Sci. 77: 223-233.

Deen, A., S. Vyas, M. Jain and M.S. Sahani. 2003b. Explanation of no or low sperm motility in camel semen. Isr. J. Vet. Med. 59: 24-27.

El-Badry, D.A., R.H. Mohamed, H.A. El-Metwally and T.R. Abo AlNaga. 2017. The effect of some cryoprotectants on dromedary camel frozen-thawed semen. Reprod. Dom. Anim. 52: 522-525.

El-Bahrawy, K.A. 2010. Effect of Seminal Plasma Centrifugation for Viscosity Elimination on Cryopreservation of Dromedary Camel Semen. Nature and Science. 8: 196-201.

El-Hassanein, E. 2003. An invention for easy semen collection from dromedary camels, El- Hassanein camel dummy. In: Skidmore JA, Adams GP, editors. Recent advances in camelid reproduction, New York-Ithaca. p.1-7.

Fatnassi, M., B. Padalino, D. Monaco, L. Aubé, T. Khorchani, G.M. Lacalandra and M.Hammadi. 2014. Effect of different management systems on rutting behavior and behavioral repertoire of housed Maghrebi male camels (Camelus dromedarius). Trop. Anim. Health. Prod. 46: 861-867.

Fatnassi, M., F. Elhouch, D. Monaco, T. Khorchani, G.M. Lacalandra and M. Hammadi. 2016. Variation of sperm characteristics among ejaculated semen fractions of dromedary camels (Camelus dromedarius). In: Proceedings of the $18^{\text {th }}$ International Congress on animal reproduction (ICAR). France. P 296.

Fuerst-Waltl, B., H. Schwarzenbacher, C. Perner and Sölkner J. 2006. Effects of age and environmental factors on semen production and semen quality of Austrian Simmental bulls. Anim. Reprod. Sci. 95: 27-37.

Hammadi, M., O. Zarrouk, A. Barmat, A. Trimeche, T. Khorchani, G. Khaldi. 2008. Characterization and conservation of Maghrebi camel semen. In: WBC/ICAR Satellite Meeting on Camelid Reproduction. Budapest. P 32-36.

Kershaw-Young, C.M., C. Stuart, G. Evans and W.M.C. Maxwell. 2013. The effect of glycosaminoglycan enzymes and proteases on the viscosity of alpaca seminal plasma and sperm function. Anim. Reprod. Sci. 138: 261-267.

Malo, C., E.G. Crichton and J.A. Skidmore. 2017. Optimization of the cryopreservation of dromedary camel semen: cryoprotectant and their concentration and equilibration times. Cryobiology. 74: $141-147$.

Mathevon, M., M.M. Buhr and J.C.M. 1998. Dekkers Environmental, Management, and Genetic Factors Affecting Semen Production in Holstein Bulls. J. Dairy Sci. 81: 3321-3330.

Monaco, D., M. Fatnassi, B. Padalino, L. Aubé, T. Khorchani, M Hammadi and G.M. Lacalandra. 2015. Effects of a GnRH 
administration on testosterone profile, libido and semen parameters of dromedary camel bulls. Res. Vet. Sci. 102: 212216.

Monaco, D., M. Fatnassi, B. Padalino, M. Hammadi, T. Khorchani and G.M. Lacalandra. 2016. Effect of a-Amylase, Papain, and Spermfluid $\circledast$ treatments on viscosity and semen parameters of dromedary camel ejaculates. Res. Vet. Sci. 105: 5-9.

Morton, K.M., J.L. Vaughan and W.M.C. Maxwell. 2008. The Continued Development of Artificial Insemination Technology in Alpacas. Rural Industries Research and Development Corporation, Kingston.

Morton, K.M., M. Billah and J.A. Skidmore. 2011. Effect of green buffer storage on the fertility of fresh camel semen after artificial insemination. Reprod. Dom. Anim. 46: 554-557.

Morton, K.M., M. Billah and J.A. Skidmore. 2013. Effect of sperm diluent and dose on the pregnancy rate in dromedary camels after artificial insemination with fresh and liquid-stored semen. J. Cam. Sci. 6: 49-62.

Musa, B., H. Sieme, H. Merkt, B. Hago, M.J. Cooper, W.R. Allen and W. Jöchle. 1993. Manipulation of reproductive functions in male and female camels. Anim. Reprod. Sci. 33: 289-306.

Padalino, B., D. Monaco and G.M. Lacalandra. 2015. Male camel behavior and breeding management strategies: how to handle a camel bull during the breeding season? Emir. J. Food. Agr. 27: 338-349.

Senger, P.L. 2005. Reproductive Behaviour. In: Pathways to
Pregnancy and Parturition Pullman. WA: Current Conceptions Print Pullman. P 240-265.

Sieme, H., Katila T. and Klug E. 2004. Effect of semen collection practices on sperm characteristics before and after storage and on fertility of stallions. Theriogenology. 61: 769-784.

Skidmore, J.A., K.M. Morton and M. Billah. 2013. Artificial Insemination in Dromedary Camels. Anim. Reprod. Sci. 136: 178-186.

Tibary, A. and A. Anouassi. 1997. Male breeding soundness examination In: Actes Editions, Institut agronomique et Veterinaire Hassan II. Theriogenology camelidae, Ist Edition, UAE, pp. 79-114.

Vyas, S., P. Goswami, A.K. Rai, and N.D. Khanna. 1998. Use of tris and lactose extenders in preservation of camel semen at refrigerated temperature. Ind.Vet. J. 75: 810-812.

Wani, N.A., M. Billah and J.A. Skidmore. 2008. Studies in liquefaction and storage of ejaculated dromedary camel (Camelus dromedarius) semen. Anim. Reprod. Sci. 109: 309-318.

Zeidan, A.E.B., A.M. El-Sarabassy, Y.A. Dowidar, A.M. Ashour, A.M. Abd El-Salam and M.H. Arafat. 2014. Impact of different extenders on semen quality and enzymatic activities of the male dromedary camel during storage at $5^{\circ} \mathrm{C}$ for up to 4 days. Egypt J. Basic. Appl. Physiol. 14: 329-348.

Ziapour, S., A. Niasari-Naslaji, M. Mirtavousi, M. Keshavarz, A. Kalantari and H. Adel. 2014. Semen collection using phan,tom in dromedary camel. Anim. Reprod. Sci. 151: 15-21. 